\title{
Coenzyme Q10 Ameliorates Cadmium Induced Reproductive Toxicity in Male Rats
}

\author{
R. SAHA ${ }^{1}$, S. ROYCHOUDHURY ${ }^{1}, K_{\text {KAR }}$, A. C. VARGHESE ${ }^{3}$, P. NANDI $^{4}$, \\ G. D. SHARMA ${ }^{5}$, G. FORMICKI ${ }^{6}$, P. SLAMA ${ }^{7}$, A. KOLESAROVA ${ }^{8}$
}

${ }^{1}$ Department of Life Science and Bioinformatics, Assam University, Silchar, India, ${ }^{2}$ Mediland Hospital and Research Centre, Itkhola, Silchar, India, ${ }^{3}$ Astra Fertility Group, Mississauga, Ontario, Canada, ${ }^{4}$ Department of Environmental Science, University of Calcutta, India, ${ }^{5}$ Atal Bihari Vajpayee University, Bilaspur, India, ${ }^{6}$ Department of Zoology of Vertebrates, Institution of Biology, Pedagogical University of Cracow, Poland, ${ }^{7}$ Department of Animal Morphology, Physiology and Genetics, Mendel University in Brno, Brno, Czech Republic, ${ }^{8}$ Department of Animal Physiology, Faculty of Biotechnology and Food Sciences, Slovak University of Agriculture in Nitra, Nitra, Slovak Republic

Received August 11, 2018

Accepted November 26, 2018

\section{Summary}

This study aimed at investigating the protective role of CoQ10 against cadmium (Cd)-induced reproductive toxicity in male rats. Adult male Wistar rats were exposed to an acute dose of $\mathrm{Cd}$ (25 mg/kg bwt; Cd group), Cd+CoQ10 (25 mg/kg bwt Cd+10 mg CoQ10; Cd-Q10 group) and distilled water (control) in vivo for 15 consecutive days and semen quality was assessed. A significant reduction was noted in sperm concentration, progressive motility, morphology and DNA integrity in both Cdand Cd-Q10 groups in comparison to control indicating Cd-induced testicular lipid per oxidation (LPO) and decline in indigenous antioxidant defense system as measured by total antioxidant capacity $($ TAC) $(p<0.05)$. However, simultaneous co-administration of CoQ10 along with $\mathrm{Cd}$ (Cd-Q10 group) was able to improve sperm concentration, motility, progressive motility, morphology, DNA integrity, and testicular TAC as well as lower LPO compared to Cd group $(p<0.05)$. Results indicate that used dose of CoQ10 is capable of moderately ameliorating reproductive toxicity of $\mathrm{Cd}$ by improving semen quality and reducing testicular oxidative stress.

\section{Key words}

Rat • Sperm • Oxidative stress • DNA damage • Cadmium

\section{Corresponding author}

S. Roychoudhury, Department of Life Science and Bioinformatics, Assam University, Silchar 788011, India. E-mail: shubhadeep1@gmail.com

Cadmium $(\mathrm{Cd})$ is a persistent heavy metal with a wide range of industrial consequences (Adamkovicova et al. 2016). Its routes of entry to the organism include inhalation of contaminated air, fumes and dusts, tobacco smoke, contaminated of food and water, and occasionally through ingestion at work place (Oyinloye et al. 2016). Basic mechanism of $\mathrm{Cd}$ toxicity involves excessive production of reactive oxygen species (ROS) leading to lipid per oxidation (LPO) and eventually oxidative stress. Co-enzyme Q10 (2, 3-dimethyl-6-ten-isoprene parabenzoquinone) is a naturally occurring lipophilic antioxidant molecule located primarily in the hydrophobic domain of mitochondrial inner membrane of phospholipid bilayer and other plasma membranes. It stimulates cell growth and inhibits cell death (Tawfik 2015) by scavenging free radicals and preventing the instigation and transmission of LPO in cellular bio-membranes (Cervellati and Grecoa 2016). The aim of this in vivo study was to investigate the efficacy of CoQ10 in combating the reproductive toxicity of $\mathrm{Cd}$ in male rats. After obtaining approval from the 
institutional animal ethics committee, male Wistar rats of reproductive age were administered cadmium chloride $\left(\mathrm{CdCl}_{2}\right)$ orally every morning for 15 consecutive days, and divided into 3 groups each consisting of 5 animals. Control group received distilled water, whereas $\mathrm{Cd}$ group received $\mathrm{Cd}$ at $25 \mathrm{mg} / \mathrm{kg}$ bwt which is $1 / 5^{\text {th }}$ of $\mathrm{LD}_{50}$, and Cd-Q10 group received $\mathrm{Cd}+\mathrm{CoQ} 10(25 \mathrm{mg} / \mathrm{kg}$ bwt $+10 \mathrm{mg} / \mathrm{kg}$ bwt), respectively. Initial and final body weights were recorded prior to sacrifice by cervical dislocation on $16^{\text {th }}$ day. Pair of testes and cauda epididymis was dissected out from each animal by laprotomy, gently rinsed in phosphate buffered saline (PBS, pH 7.4), cleaned off the adhering tissues and weighed. Cauda epididymis of each animal was gently minced in $2 \mathrm{ml}$ PBS and incubated at $37^{\circ} \mathrm{C}$ for semen analysis including DNA integrity (Sarathchandiran et al. 2014). Sperm concentration, motility and progressive motility were assessed by mounting the sperm suspension in Makler Counting Chamber (Sefi Medical Instruments, Germany) and observed under $20 \mathrm{x}$ magnification using phase contrast microscope (Labomed-LX 300) (Roychoudhury et al. 2010a). Sperm morphology was examined using Giemsa staining (Roychoudhury et al. 2010b). Sperm DNA integrity was studied by measuring the DNA fragmentation index under fluorescent microscope (Olympus-CX 31-TR) using acridine orange dye (Varghese et al. 2009). Testicular oxidative stress was determined by LPO measured as the amount of malondialdehyde produced (Paunovic et al. 2017) and TAC was measured in testis by commercially available kit (Roychoudhury et al. 2016). Each experiment was performed thrice. Significant differences between the experiments were evaluated using one way ANOVA with Scheffe's post hoc comparison of SPSS version 21 software. Differences from control at $\mathrm{p}<0.05$ were considered significant. In comparison to control, there was a significant decline in testicular weight in both $\mathrm{Cd}-$ and Cd-Q10 groups $(\mathrm{p}=0.035)$. Sperm concentration, motility, progressive motility, morphology, DNA integrity and testicular TAC were significantly lower in both $\mathrm{Cd}$ - and Cd-Q10 groups compared to control $(p<0.05)$. Marked elevation was noted in the level of LPO in both Cd- and Cd-Q10 groups in comparison to control $(\mathrm{p}<0.05)$. Co-administration of CoQ10 was capable of moderately recovering the toxic effect of $\mathrm{Cd}$ as sperm concentration, motility, progressive motility, morphology, DNA integrity and testicular TAC increased significantly in Cd-Q10 group, while a significant reduction in LPO was noted in Cd-Q10 group in comparison to $\mathrm{Cd}$ group, respectively $(\mathrm{p}<0.05)$ (Figs $1 \mathrm{~A}-\mathrm{C})$.
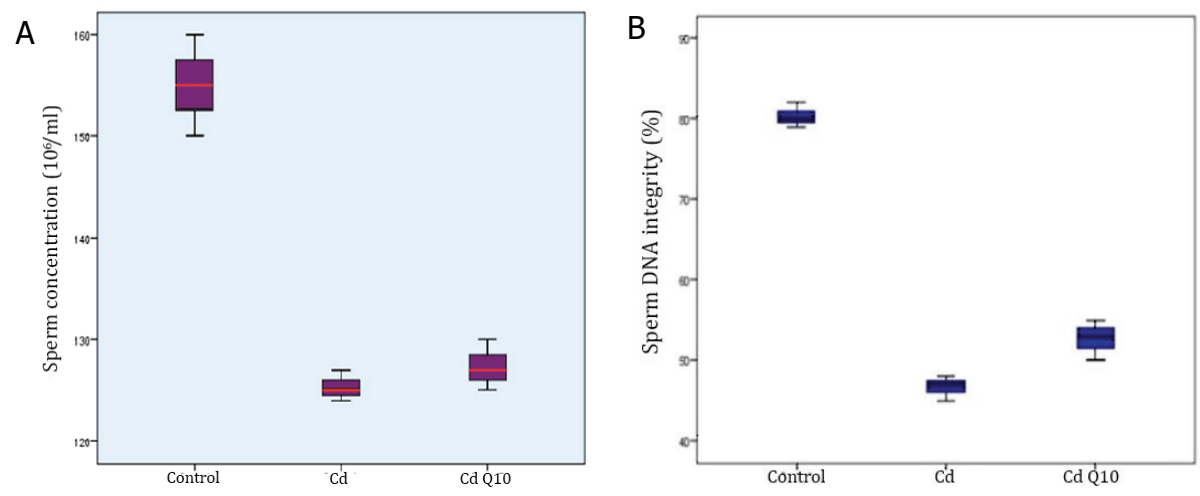

Fig. 1. Moderate amelioration of cadmium (Cd) induced reproductive toxicity by coenzyme Q10 (CoQ10) in male rats: (A) sperm concentration, (B) sperm DNA integrity, and (C) testicular lipid peroxidation (LPO) in control, Cd and $\mathrm{Cd}-\mathrm{Q} 10$ groups

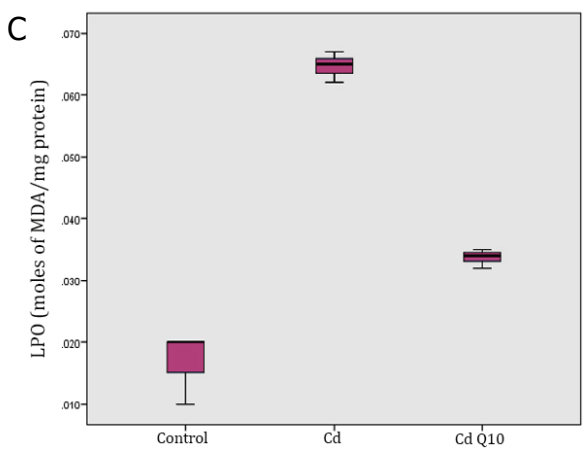

Spermatogenesis is a complex process that involves a phase of proliferative expansion, meiosis, and cytodifferentiation (Jan et al. 2012). In the rat, the coordinated spatial associations of developmental germ cell types occurs in a time regulated fashion, and accordingly the seminiferous epithelium can be subdivided 
into fourteen stages (Leblond and Clermont 1952, Oakberg 1956). The time necessary for a cell to ascend one stage above the original cell in a spermatogenic cycle map is 13.3 days and the duration of spermatogenesis is 53.2 days in Wistar rats as used in the present study (Huckins 1965). A number of characteristics including the timing of differentiation process and spermatozoa morphology are also unique to rats although the general process of spermatogenesis is highly conserved across mammals (de Krester and Kerr 1988, Russell et al. 1993). In earlier studies, $\mathrm{Cd}$ was found to induce necrosis in testicular tissue that adds to weight loss in testes (Wang et al. 2007, Toman et al. 2011). Chronic administration of a lower dose of $\mathrm{Cd}$ ( $5 \mathrm{mg} / \mathrm{kg}$ bwt) for a period of 6-8 weeks caused a decline in sperm concentration, motility, progressive motility and morphology in rats (Akunna et al. 2017, El-Demerdash et al. 2004). Cadmium was also found to impair rabbit sperm motility, morphology and membrane integrity even at a much lower dose $(0.62 \mu \mathrm{g} \mathrm{CdCl} / \mathrm{ml})$ in vitro (Roychoudhury et al. 2010). In the present study, Cd-induced toxicity was evident from reduction in sperm concentration, motility, progressive motility, morphology, DNA integrity and TAC together with an increase in testicular LPO in both Cd- and Cd-Q10 groups, which is directly related to male fertility and recognized to have putative roles in diminishing sperm quality through testicular damage (Akunna et al. 2017). Cadmium is known to alter testicular function by inducing oxidative stress (Amara et al. 2006) which is a common pathology in approximately half of all infertile men, and is further associated with pathogenesis of sperm DNA damage (Aitken et al. 2010). A lower dose of $1 \mathrm{mg} / \mathrm{kg}$ bwt administered to adult male rats for a period of 5-8 weeks showed elevated LPO and relative depletion of testicular antioxidant levels (Acharya et al. 2008). Coenzyme Q10 is a potent antioxidant with the capacity to neutralize tocopheroxyl radicals in its reduced form ubiquinol (Nagaoka et al. 2000). Protective effect of CoQ10 has been shown on sperm motility, LPO and DNA fragmentation in vitro (Talevi et al. 2010). Coenzyme Q10 when administered to adult male rats at $10 \mathrm{mg} / \mathrm{kg}$ bwt was able to ameliorate testicular toxicity induced by $\mathrm{Cd}$ at the dose $5 \mathrm{mg} / \mathrm{kg}$ bwt (Abdel-Hady and Abdel Rahman 2011). In the present study, moderate improvement in sperm concentration, motility, progressive motility, morphology, DNA integrity and testicular TAC was noted in Cd-Q10 group with $25 \mathrm{mg} / \mathrm{kg}$ bwt $\mathrm{Cd}$ co-administered along with $10 \mathrm{mg} \mathrm{CoQ} 10$ for a period of 15 days in comparison to Cd group with $25 \mathrm{mg} / \mathrm{kg}$ bwt Cd-exposure.

In conclusion, our results indicate that $\mathrm{CoQ} 10$ at a low dose of $10 \mathrm{mg} / \mathrm{kg}$ bwt used in the present study was possibly capable of nullifying the ability of a high dose of $25 \mathrm{mg} / \mathrm{kg}$ bwt Cd to replace redox-active metals and hence did not allow $\mathrm{Cd}$ to hinder redox scavenging enzymes. These findings support the use of CoQ10 as a potential antidote in the management of $\mathrm{Cd}$ induced reproductive toxicity and male infertility through mechanisms involving reduction of testicular oxidative stress and improvement of semen quality.

\section{Conflict of Interest}

There is no conflict of interest.

\section{Acknowledgements}

This work was supported by Department of Biotechnology, Government of India grant release no. BT/265/NE/TBP/2011, Assam University Silchar, and the Ministry of Education, Science, Research and Sport of the Slovak Republic projects VEGA 1/0039/16, APVV-160170 .

\section{References}

ABDEL-HADY ESK, ABDEL-RAHMAN GH: Protective effect of coenzyme Q10 on cadmium-induced testicular damage in male rabbits. Am Eur J Toxicol Sci 3: 153-160, 2011.

ACHARYA UR, MISRA M, PATRO J, PANDA MK: Effect of vitamins $C$ and $E$ on spermatogenesis in mice exposed to cadmium. Reprod Toxicol 25: 84-88, 2008.

ADAMKOVICOVA M, TOMAN R, MARTINIAKOVA M, OMELKA R, BABOSOVA R, KRAJCOVICOVA V, GROSSKOPF B, MASSANYI P: Sperm motility and morphology changes in rats exposed to cadmium and diazinon. Reprod Biol Endocrinol 14: 42, 2016.

AITKEN RJ, DE IULIIS GN, FINNIE JM, HEDGES A, MCLACHLAN RI: Analysis of the relationships between oxidative stress, DNA damage and sperm vitality in a patient population: development of diagnostic criteria. Hum Reprod 25: 2415-2426, 2010. 
AKUNNA G, OBIKILI E, ANYANWU E, ESOM E: Protective and curative role of Citrus sinensis peel on cadmiuminduced testicular and spermatic damage: a morphometric and immunohistochemical evaluation using monoclonal antibodies against Ki-67 and proliferating cell nuclear antigen. Eur J Anat 21: 19-30, 2017.

AMARA S, ABDELMELEK H, GARREL C, GUIRAUD P, DOUKI T, RAVANAT JL, FAVIER A, SAKLY M, BEN RHOUMA K: Influence of static magnetic field on cadmium toxicity: study of oxidative stress and DNA damage in rat tissues. $J$ Trace Elem Med Biol 20: 263-269, 2006.

CERVELLATI R, GRECO E: In vitro antioxidant activity of ubiquinone and ubiquinol, compared to vitamin E. Helv Chimica Acta 99: 41-45, 2016.

DE KRESTER DM, KERR JB: The cytology of the testis. In: The Physiology of Reproduction. KNOBIL E, NEILL J (eds), Raven Press, New York, 1988, pp 837-932.

EL-DEMERDASH FM, YOUSEF MI, KEDWANY FS, BAGHDADI HH: Cadmium-induced changes in lipid peroxidation, blood haematology, biochemical parameters and semen quality of male rats: protective role of vitamine E and $\beta$-caretene. Food Chem Toxicol 42: 1564-1571, 2004.

HUCKINS C: Duration of spermatogenesis in pre- and post-pubertal wistar rats. Anat Rec 151: 364, 1965.

JAN SZ, HAMER G, REPPING S, DE ROOIJ DG, VAN PELT AMM, VORMER TL: Molecular control of rodent spermatogenesis. Biochim Biophys Acta 1822: 1838-1850, 2012.

LEBLOND CP, CLERMONT Y: Definition of the stages of the cycle of the seminiferous epithelium in the rat. Ann N Y Acad Sci 55: 548-573, 1952.

NAGAOKA S, INOUE M, NISHIOKA C, NISHIOKU S, OHGUCHI C, OKHARA K, MUKAI K, NAGASHIMA U: Tunneling effect in antioxidant, prooxidant and regeneration reactions of vitamin E. J Phys Chem B 104: 856-862, 2000.

OAKBERG EF: Duration of spermatogenesis in the mouse and timing of stages of the cycle of the seminiferous epithelium. Am J Anat 99: 507-516, 1956.

OYINLOYE BE, AJIBOYE BO, OJO OA, MUSA HM, ONIKANNI SA, OJO AA: Ameliorative potential of Aframomum melegueta extract in cadmium-induced hepatic damage and oxidative stress in male Wister rats. J Appl Pharm Sci 6: 94-99, 2016.

PAUNOVIC MG, MATIC MM, OGNJANOVIC BI, SAICIC ZS: Antioxidant and haematoprotective activity of coenzyme Q10 and vitamin E against cadmium-induced oxidative stress in Wistar rats. Toxicol Ind Health 33: 746-756, 2017.

ROYCHOUDHURY S, MASSANYI P, BULLA J, CHOUDHURY MD, LUKAC N, FILIPEJOVA T, TRANDZIK J, TOMAN R, ALMASIOVA V: Cadmium toxicity at low concentration on rabbit spermatozoa spermatozoa motility, morphology and membrane integrity in vitro. J Environ Sci Health A Tox Hazard Subst Environ Eng $\mathbf{4 5}$ : 1374-1383, 2010a.

ROYCHOUDHURY S, MASSANYI P, BULLA J, CHOUDHURY MD, STRAKA L, LUCAK N, FORMICK G, DANKOVA M, BARDOS L: In vitro copper toxicity on rabbit spermatozoa motility, morphology and cell membrane integrity. J Environ Sci Health A 45: 1482-1491, 2010 b.

ROYCHOUDHURY S, SHARMA R, SIKKA S, AGARWAL A: Diagnostic application of total antioxidant capacity in seminal plasma to assess oxidative stress in male factor infertility. J Assist Reprod Genet 33: 627-635, 2016.

RUSSELL LD, ETTLIN RA, HIKIM APS, CLEGG ED: Histological and histopathological evaluation of the testis. Int J Androl 16: 83, 1993.

SARATHCHANDIRAN I, KADALMANI B, NAVANEETHAKRISHNAN S: Evaluation of spermatotoxic activity of Clerodendrum Serratum in male albino rats. Int J Biol Pharma Res 5: 16-21, 2014.

TALEVI R, BARBATO V, FIORENTINO I, BRAUN S, LONGOBARDI S, GUALTIER R: Protective effects of in vitro treatment with zinc, d-astertate and coenzyme Q10 on human sperm motility, lipid peroxidation and DNA fragmentation. Reprod Biol Endocrinol 11: 18, 2013.

TAWFIK MK: Combination of coenzyme Q10 with methotrexate suppresses Freund's complete adjuvant induced synovial inflammation with reduced hepatotoxicity in rats: effect on oxidative stress and inflammation. Int Immunopharmacol 24: 80-87, 2015.

TOMAN R, ADAMKOVICOVA M, HLUCHY S, CABAJ M, GOLIAN J: Quantitative analysis of the rats testis after an acute cadmium and diazinon administration. Animal Sci Biotechnol 44: 188-191, 2011. 
VARGHESE AC, BRAGAIS FM, MUKHOPADHYAY D, KUNDU S, PAL M, BHATTACHARYYA AK, AGARWAL A: Human sperm DNA integrity in normal and abnormal semen samples and its correlation with sperm characteristics. Andrologia 41: 1-9, 2009.

WANG B, SCHNEIDER SN, DRAGIN N, GIRIJASANKAR K, DALTON TP, HE L, MILLER ML, STRINGER KF, SOLEIMANI M, RICHARDSON DD, NEBERT DW: Enhanced cadmium-induced testicular necrosis and renal proximal tubule damage caused by gene-dose increase in a Slc 39a8-transgenic mouse line. Am J Physiol Cell Physiol 291: 523-535, 2007. 